SINET: Ethiop. J. Sci., 25(2):191-204, 2002

(C) Faculty of Science, Addis Ababa University, 2002

ISSN: 0379-2897

\title{
VARIATION AND ASSOCIATION ANALYSIS IN GRASS PEA
} (LATHYRUS SATIVUS L.)

\author{
Wuletaw Tadesse ${ }^{1}$ and Endashaw Bekele ${ }^{2}$ \\ ${ }^{1}$ Adet Research Centre P.O. Box 08, Bahir Dar, Ethiopia \\ E-mail: Wtadesse2002@yahoo.com \\ ${ }^{2}$ Department of Biology, Faculty of Science, Addis Ababa University \\ PO Box 1176, Addis Ababa, Ethiopia
}

\begin{abstract}
The study was conducted on 50 landrace populations of grass pea at Adet Research Center, Ethiopia, using Randomised Complete Block Design in three replications to determine morphological variability and character associations. Evaluations were made on plant and yield characters from eight plants tagged randomly from each plot. The data were subjected to Analysis of Variance (ANOVA), heritability, correlation and cluster analyses. Higher mean and CV values were recorded for most of the agronomic traits for populations collected from Gondar region and the higher altitude group $(>2500 \mathrm{~m})$ indicating the presence of high genetic diversity in this region and altitude group. Phenotypic coefficient of variation (PCV) was slightly higher than genotypic coefficient of variation (GCV) for all the characters studied signifying that genotypic factors exerted reasonable effect in estimating the variation. The wide difference between PCV $(22.4 \%)$ and GCV $(13.0 \%)$ for seed yield per plant indicated the complexity of this trait and the important role of other factors such as environment in influencing yield potential in addition to the genetic factors. The strong positive association of pods per plant, 100 seed weight and primary branches per plant with seed yield indicated the possibility of selecting lines for yield improvement based on these characters at the very early stage of the grass pea breeding program.
\end{abstract}

\section{Key words/phrases: Correlation grass pea, heritability, Lathyrus sativus, variation}

\section{INTRODUCTION}

Grass pea (Lathyrus sativus) belongs to the genus Lathyrus in the tribe Vicieae of the Leguminosae family (Purseglove, 1968; Goyder, 1986). It is a selfpollinated annual vine closely resembling field pea in growth habit but its leaflets are long and grass shaped. The origin of grass pea is unknown (Thulin, 1983). But Purseglove (1968) postulated southern Europe and western India as centres of origin. Vavilov (1951) and lately Asfaw Telaye et al. (1994) considered Ethiopia as a primary source of diversity for grass pea.

Grass pea is a highly popular food and feed legume in the farming system of drought affected areas due to its tolerance to drought, flooding and diseases 
and its importance in ameliorating soil fertility (Campbell and Tiwari, 1997) even though heavy consumption of grass pea seed is associated with the development of lathyrism, a crippling disorder, in humans. It is dominantly cultivated in Ethiopia, India, Pakistan, Bangladesh and Nepal (Bharati, 1986; Wuletaw Tadesse et al., 1997). According to Kaul et al. (1986), grass pea accounts for more than twenty five percent of the area as well as production of all pulses grown in Bangladesh. Furthermore Lal et al. (1986) indicated that grass pea is the third largest pulse crop of India in area after chickpea and pigeon pea. In Ethiopia, it is the third important pulse crop after fababean and chickpea with 142,170 hectares of production area and 1,047,440 quintals of production (CSA, 1998).

Melaku Werede (1988), Endashaw Bekele (1983) and Dawit Tadesse (1994) showed that the valuable genetic diversity of several crops is under constant danger of being irretrievably lost due to natural calamities such as drought, replacement of the landrace by genetically uniform crop varieties and change and development in land use. In the case of grass pea under Ethiopian condition, the association of grass pea with lathyrism and the cereal based extension program coupled with the absence of improved varieties for grass pea production are important factors leading to the reduction of grass pea production and genetic resources (Wuletaw Tadesse, 1999). Hence there is a great need for germplasm collection and maintenance to promote a grass pea breeding program for developing varieties with high grain yield and low toxin content.

Genetic variability studies are essential to undertake germplasm collection for ex-situ conservation and to identify sites with high genetic diversity for in situ conservation (Abebe Demissie and Bjornstand, 1996; Endashaw Bekele, 1983). Furthermore, genetic variation in crop plants for characters of agronomic importance leading to the determination of complex characters such as 'yield' should be determined since it forms the base in crop improvement. In such an improvement process, Thorpe (1976) indicated that character associations are important to indicate common elements of epigenetic control and/or similar response of characters to selection pressure. However, such studies were not carried out for grass pea in Ethiopia. Hence, this study was carried out with the following objectives.

1. To study the magnitude and variation of some morphological characters and their patterns of distribution.

2. To identify sites of high genetic variation for in-situ conservation and generate information for further grass pea germplasm collection.

3. To determine the associations between different agronomic characters in grass pea. 


\section{MATERIALS AND METHODS}

The study was carried out from September 1998 to February 1999 at Adet Research Centre which is located at $37^{\circ} 29^{\prime} \mathrm{E}$ and $11^{\circ} 16^{\prime} \mathrm{N}$ and at an altitude of $2240 \mathrm{~m}$ above sea level in Gojam Administrative Zone, Ethiopia. The soil is Vertisol with $\mathrm{pH}$ level of 6.0. The rainfall (1230 mm per annum) and other weather variables of the test period were generally conducive for normal growth of grass pea.

Fifty grass pea landrace populations, which are believed to represent the national collection in the Biodiversity Research and Conservation Institute of Ethiopia, were used in this study (Table 1). These populations were selected from all grass pea growing administrative regions based on different altitude groups of legume production classified by Asfaw Telaye et al. (1994) as low (<1900m), mid (1901-2250 m), high (2551-2550 m) and very high (>2550 m) altitudes. Planting of the populations were carried out in the first week of September at Adet Research Center experimental field in a plot size of $4 \mathrm{~m}^{2}$ (four rows of $5 \mathrm{~m}$ length and $0.2 \mathrm{~m}$ row spacing) each, using randomised complete block design (RCBD) in three replications at a seeding rate of 40 $\mathrm{kg} / \mathrm{ha}$. The spacing between plots and blocks were 1 and $1.5 \mathrm{~m}$, respectively. Fertilizer and irrigation water were not applied. Eight plants from the central two rows in each plot were tagged randomly and evaluated for days to $50 \%$ flowering, days to $90 \%$ maturity, number of pods/plant, plant height $(\mathrm{cm})$, 100 seed weight $(\mathrm{g})$, seed yield per plant $(\mathrm{g})$ and harvest index per plant $(\%)$.

\section{Statistical analyses}

Analyses of variances were determined for all morphological characters using MSTAT C soft ware. Clustering of the populations was carried out using mean values of morphological characters with the help of SPSS software. Correlation analysis was also carried out using the same software. Genetic and phenotypic correlations, variance components, coefficient of variation, heritability and genetic advance were determined as follows following Johanson et al. (1955).

Genotypic correlation $=\frac{\operatorname{cov}(\mathrm{x}, \mathrm{y})}{\sqrt{\left(\mathrm{S}_{\mathrm{gx}}^{2} \times \mathrm{S}_{\mathrm{gy}}^{2}\right)}}$ where $\operatorname{COV} \mathrm{xy}$ is the genetic covariance between two traits, $S^{2}$ gx and $S_{\text {gy }}^{2}$ are the genetic covariances of the two traits. Phenotypic correlation $=\frac{\operatorname{cov}(\mathrm{x}, \mathrm{y})}{\sqrt{\left(\mathrm{S}_{\mathrm{px}}^{2} \times \mathrm{S}_{\mathrm{py}}^{2}\right)}}$ where $\mathrm{COV} x \mathrm{x}$ is the phenotypic covariance between two traits, $S_{p x}^{2}$ and $S_{p y}^{2}$ are the phenotypic covariances of the two traits. Cov xy for each pair of traits was computed from the analysis of covariance in a similar manner as the analysis of variance. 
Phenotypic variance $(\mathrm{vp})=$ genotype $\mathrm{ms} / \mathrm{r}$; error variance $(\mathrm{ve})=$ error $\mathrm{ms} / \mathrm{r}$, genotypic variance $(\mathrm{vg})=\mathrm{vp}$-ve, where $\mathrm{r}=$ number of replications and $\mathrm{ms}=$ mean squares. Phenotypic coefficient of variation $(\mathrm{pcv})=100 \times \sqrt{(v p)} / \mathrm{m}$ and genotypic coefficient of variation $(\mathrm{gcv})=100 \times \sqrt{(v g)} / \mathrm{m}$ where $\mathrm{m}=$ the mean value. Heritability $\left(\mathrm{h}^{2}\right)=\mathrm{vg} / \mathrm{vp}$ and genetic advance $(\mathrm{GS})=(\mathrm{I})\left(\mathrm{h}^{2}\right) \sqrt{(v p)}$ where $\mathrm{I}=$ selection differential (2.06 for selecting $5 \%$ of the genotypes); gs (\%of the mean $)=(\mathrm{gs} / \mathrm{m}) \times 100$.

Table 1. Plant genetic resource Center (PGRC/E) acc no., administrative region, county and altitude of the collecting sites of the populations.

\begin{tabular}{|c|c|c|c|c|}
\hline No. & cc. no. & Region & County & Altitude (m) \\
\hline 1 & 46003 & Shoa & Yerer & 2050 \\
\hline 2 & 46008 & Shoa & Muketurie & 2240 \\
\hline 3 & 46012 & Gojam & Mota & 2550 \\
\hline 4 & 46016 & Shoa & Sayadibir & 2700 \\
\hline 5 & 46020 & Shoa & Ambo & 2235 \\
\hline 6 & 46023 & Shoa & Menagesha & 2500 \\
\hline 7 & 46024 & Shoa & Kara & 2460 \\
\hline 8 & 46027 & Shoa & Ginchi & 2420 \\
\hline 9 & 46030 & Gojam & Enebsie & 2300 \\
\hline 10 & 46033 & Gondar & Este & 2330 \\
\hline 11 & 46034 & Wollo & Wogeltena & 2090 \\
\hline 12 & 46035 & Wollo & Wogeltena & 2375 \\
\hline 13 & 46042 & Gojam & Debrework & 2540 \\
\hline 14 & 46044 & Gojam & Shebelberenta & 2410 \\
\hline 15 & 46049 & Gojam & Dejen & 2490 \\
\hline 16 & 46050 & Gojam & Felegebrhan & 2700 \\
\hline 17 & 46073 & Gojam & Yetnora & 2420 \\
\hline 18 & 46099 & Wollo & Kalu & 1880 \\
\hline 19 & 46100 & Wollo & Bistima & 2000 \\
\hline 20 & 46106 & Wollo & Wodere & 1950 \\
\hline 21 & 46110 & Wollega & Kelem & 1600 \\
\hline 22 & 46111 & Wollo & Sulula & 1700 \\
\hline 23 & 207493 & Gondar & Kemkem & 2400 \\
\hline 24 & 207496 & Tigray & Didiba & 2200 \\
\hline 25 & 207497 & Tigray & GentaAfeshum & 2200 \\
\hline 26 & 207499 & Gondar & Gondar & 2600 \\
\hline 27 & 207566 & Tigray & Hintalo & 2150 \\
\hline 28 & 207567 & Tigray & Laymaychew & 2100 \\
\hline 29 & 208449 & Gojam & Adet & 2300 \\
\hline 30 & 211511 & Wollega & Nejo & 1740 \\
\hline 31 & 215247 & Wollo & --Gobalafto & 1900 \\
\hline 32 & 219945 & Tigray & Adiabeiti & 1870 \\
\hline 33 & 219946 & Tigray & Laymaichew & 2080 \\
\hline 34 & 219949 & Tigray & Adiabeiti & 2150 \\
\hline 35 & 219950 & Tigray & Adwa & 2230 \\
\hline 36 & 219952 & Tigray & Naendre & 1700 \\
\hline 37 & 220118 & Ertrea & Mendefera & 1980 \\
\hline 38 & 226001 & Wollo & Debresina & 2400 \\
\hline 39 & 226006 & Wollo & Kelela & 2500 \\
\hline 40 & 226010 & Wollo & Legambo & 2640 \\
\hline 41 & 223219 & Tigray & Tserai & 1930 \\
\hline 42 & 226014 & Gondar & Este & 2645 \\
\hline 43 & 226019 & Gojam & Bahirdar & 1685 \\
\hline 44 & 228495 & Gojam & Awbel & 2400 \\
\hline 45 & 236711 & Gojam & Damot & 1840 \\
\hline 46 & 46107 & Gondar & Maksegnit & 1950 \\
\hline 47 & 236686 & Gojam & Mertolemariam & 2555 \\
\hline 48 & 436705 & Gondar & Woreta & 1800 \\
\hline 49 & 236708 & Gondar & Dabat & 2730 \\
\hline 50 & 236701 & Gojam & TisAbay & 1700 \\
\hline
\end{tabular}




\section{RESULTS AND DISCUSSION}

\section{Variations in quantitative characters}

The mean, range and coefficient of variation in agronomic traits are widely used to determine variations within and between populations (Jaradat, 1991; Sharma et al., 1995; Endashaw Bekele, 1996, Getachew Belay, 1997). Similarly, variations in grass pea were determined in the present study. As indicated in Table 2, mean yield per plant ranged from 42-132.9 $\mathrm{g}$ while the number of pods per plant ranged from 199-675. Days-to-flowering and maturing ranged from 39-73 and 127-165 days, respectively.

Analysis of variance showed highly significant differences between populations for days-to-maturity, pods per plant, seed yield per plant, harvest index and dry matter yield (Table 3). As indicated in Tables 4 and 5, the character that showed the highest coefficient of variation was not the same for all regions and altitude groups indicating the effect of environment on the variability of traits. Number of pods per plant showed much variation (CV= $53.7 \%$ ) in the population collected from Eritrea followed by those from Gondar region $(\mathrm{CV}=26.9 \%)$. The mean number of pods per plant, however, was highest (506 pods per plant) in the population from Gondar. Mean seed yield per plant for grass pea was highest in the population collected from Eritrea (107 g) followed by Gondar region (100.8 g/plant). The high mean and $\mathrm{CV}$ values observed in the population from Eritrea may be due to the low number of populations used from the region for the study.

Populations collected from Gondar showed the highest mean primary branches per plant while populations from Tigray showed least primary branches per plant. Plant height showed higher coefficient of variation (6.8\%) in populations collected from Eritrea. Populations from Gondar are in general long with mean heights of $120.9 \mathrm{~cm}$ (Table 4). Total biomass per plant is also high in populations from this region $(259.1 \mathrm{~g})$. Populations from Gondar and Eritrea regions showed low harvest index while populations from Wollega showed high harvest index. The low harvest index in grass pea from Gondar region and Eritrea could be due to high biomass production. Variation in phenological traits was also observed among populations from different regions. The highest coefficient of variation was observed in the population from Gondar, $1.5 \%$ for days-to-flowering and 3.2\% for days-to-maturity. Populations from Wollega took minimum days-to-flower $($ mean $=44)$ and to mature $($ mean $=132$ days) while populations from Gondar were late both to flower and mature with means of 62 and 154 days, respectively. 
Table 2. Mean values for 10 morphological characters in 50 grass pea populations of Ethiopia, 1998.

\begin{tabular}{|c|c|c|c|c|c|c|c|c|c|c|}
\hline Acc.no & PRB & PLHT & DF & DM & PPP & SPP & SW & BIOM & SY & HI \\
\hline 46003.00 & 9.00 & 101.00 & 49.00 & 142.00 & 335.00 & 3.00 & 8.00 & 147.00 & 76.00 & 57.00 \\
\hline 46008.00 & 9.00 & 104.00 & 55.00 & 141.00 & 288.00 & 3.00 & 8.00 & 152.00 & 62.00 & 42.00 \\
\hline 46012.00 & 9.00 & 119.00 & 56.00 & 145.00 & 462.00 & 3.00 & 8.00 & 228.00 & 104.00 & 44.00 \\
\hline 46016.00 & 10.00 & 104.00 & 50.00 & 140.00 & 327.00 & 3.00 & 8.00 & 145.00 & 67.00 & 42.00 \\
\hline 46020.00 & 9.00 & 103.00 & 52.00 & 140.00 & 344.00 & 3.00 & 9.00 & 159.00 & 77.00 & 46.00 \\
\hline 46023.00 & 10.00 & 103.00 & 54.00 & 138.00 & 396.00 & 3.00 & 7.00 & 155.00 & 72.00 & 85.00 \\
\hline 46024.00 & 10.00 & 103.00 & 54.00 & 141.00 & 486.00 & 3.00 & 8.00 & 219.00 & 115.00 & 48.00 \\
\hline 46027.00 & 9.00 & 104.00 & 55.00 & 142.00 & 361.00 & 3.00 & 8.00 & 158.00 & 77.00 & 44.00 \\
\hline 46030.00 & 10.00 & 111.00 & 61.00 & 145.00 & 328.00 & 3.00 & 8.00 & 179.00 & 70.00 & 36.00 \\
\hline 46033.00 & 9.00 & 122.00 & 58.00 & 144.00 & 412.00 & 3.00 & 9.00 & 197.00 & 93.00 & 43.00 \\
\hline 46034.00 & 9.00 & 116.00 & 46.00 & 143.00 & 306.00 & 3.00 & 10.00 & 164.00 & 80.00 & 48.00 \\
\hline 46035.00 & 9.00 & 106.00 & 49.00 & 145.00 & 307.00 & 3.00 & 9.00 & 149.00 & 73.00 & 48.00 \\
\hline 46042.00 & 9.00 & 112.00 & 56.00 & 144.00 & 477.00 & 3.00 & 8.00 & 206.00 & 86.00 & 46.00 \\
\hline 46044.00 & 10.00 & 118.00 & 57.00 & 147.00 & 445.00 & 3.00 & 8.00 & 184.00 & 86.00 & 48.00 \\
\hline 46049.00 & 10.00 & 117.00 & 59.00 & 151.00 & 509.00 & 3.00 & 8.00 & 220.00 & 100.00 & 44.00 \\
\hline 46050.00 & 9.00 & 119.00 & 62.00 & 144.00 & 386.00 & 3.00 & 7.00 & 159.00 & 95.00 & 42.00 \\
\hline 46077.00 & 10.00 & 109.00 & 62.00 & 152.00 & 454.00 & 3.00 & 8.00 & 292.00 & 98.00 & 41.00 \\
\hline 46099.00 & 10.00 & 106.00 & 52.00 & 141.00 & 389.00 & 3.00 & 8.00 & 195.00 & 93.00 & 46.00 \\
\hline 46100.00 & 8.00 & 113.00 & 44.00 & 134.00 & 301.00 & 3.00 & 9.00 & 144.00 & 73.00 & 47.00 \\
\hline 46106.00 & 9.00 & 118.00 & 50.00 & 142.00 & 333.00 & 3.00 & 9.00 & 172.00 & 82.00 & 48.00 \\
\hline 46110.00 & 10.00 & 194.00 & 42.00 & 130.00 & 334.00 & 3.00 & 8.00 & 123.00 & 65.00 & 52.00 \\
\hline 46111.00 & 10.00 & 117.00 & 44.00 & 140.00 & 348.00 & 3.00 & 9.00 & 168.00 & 93.00 & 54.00 \\
\hline 207493.0 & 11.00 & 121.00 & 52.00 & 148.00 & 517.00 & 3.00 & 8.00 & 259.00 & 107.00 & 43.00 \\
\hline 207496.0 & 9.00 & 94.00 & 40.00 & 127.00 & 200.00 & 3.00 & 9.00 & 86.00 & 45.00 & 51.00 \\
\hline 207497.0 & 8.00 & 104.00 & 45.00 & 136.00 & 282.00 & 3.00 & 9.00 & 143.00 & 79.00 & 53.00 \\
\hline 207499.0 & 9.00 & 122.00 & 57.00 & 145.00 & 410.00 & 3.00 & 10.00 & 186.00 & 92.00 & 47.00 \\
\hline 207566.0 & 8.00 & 93.00 & 41.00 & 130.00 & 198.00 & 3.00 & 8.00 & 87.00 & 42.00 & 40.00 \\
\hline 207567.0 & 9.00 & 110.00 & 52.00 & 143.00 & 354.00 & 3.00 & 9.00 & 159.00 & 82.00 & 50.00 \\
\hline 208449.0 & 9.00 & 107.00 & 55.00 & 142.00 & 422.00 & 3.00 & 8.00 & 206.00 & 95.00 & 46.00 \\
\hline 211511.0 & 8.00 & 94.00 & 46.00 & 135.00 & 304.00 & 3.00 & 8.00 & 121.00 & 67.00 & 54.00 \\
\hline 215247.0 & 11.00 & 120.00 & 52.00 & 140.00 & 504.00 & 3.00 & 8.00 & 229.00 & 116.00 & 48.00 \\
\hline 219945.0 & 8.00 & 95.00 & 44.00 & 135.00 & 243.00 & 3.00 & 8.00 & 115.00 & 55.00 & 48.00 \\
\hline 219946.0 & 10.00 & 114.00 & 46.00 & 142.00 & 481.00 & 3.00 & 9.00 & 209.00 & 104.00 & 50.00 \\
\hline 219949.0 & 9.00 & 115.00 & 49.00 & 141.00 & 435.00 & 3.00 & 10.00 & 193.00 & 91.00 & 45.00 \\
\hline 219950.0 & 9.00 & 101.00 & 49.00 & 135.00 & 291.00 & 3.00 & 10.00 & 145.00 & 70.00 & 44.00 \\
\hline 219952.0 & 9.00 & 122.00 & 48.00 & 142.00 & 395.00 & 3.00 & 9.00 & 205.00 & 95.00 & 45.00 \\
\hline 220118.0 & 10.00 & 107.00 & 52.00 & 148.00 & 464.00 & 3.00 & 9.00 & 226.00 & 105.00 & 44.00 \\
\hline 226001.0 & 9.00 & 110.00 & 57.00 & 142.00 & 385.00 & 3.00 & 8.00 & 182.00 & 87.00 & 45.00 \\
\hline 226006.0 & 8.00 & 115.00 & 51.00 & 135.00 & 355.00 & 3.00 & 9.00 & 182.00 & 90.00 & 46.00 \\
\hline 226010.0 & 9.00 & 122.00 & 52.00 & 140.00 & 345.00 & 3.00 & 12.00 & 177.00 & 89.00 & 64.00 \\
\hline 223219.0 & 9.00 & 105.00 & 39.00 & 135.00 & 315.00 & 3.00 & 9.00 & 141.00 & 79.00 & 56.00 \\
\hline 226014.0 & 9.00 & 120.00 & 55.00 & 165.00 & 364.00 & 3.00 & 9.00 & 217.00 & 90.00 & 43.00 \\
\hline 226019.0 & 11.00 & 121.00 & 57.00 & 143.00 & 530.00 & 3.00 & 8.00 & 231.00 & 114.00 & 49.00 \\
\hline 228495.0 & 9.00 & 103.00 & 61.00 & 145.00 & 334.00 & 3.00 & 8.00 & 166.00 & 76.00 & 46.00 \\
\hline 236711.0 & 8.00 & 122.00 & 57.00 & 150.00 & 441.00 & 3.00 & 8.00 & 257.00 & 87.00 & 42.00 \\
\hline 46106.00 & 10.00 & 123.00 & 73.00 & 156.00 & 513.00 & 3.00 & 7.00 & 289.00 & 84.00 & 35.00 \\
\hline 236686.0 & 7.00 & 106.00 & 60.00 & 148.00 & 253.00 & 3.00 & 7.00 & 107.00 & 55.00 & 53.00 \\
\hline 236705.0 & 12.00 & 125.00 & 68.00 & 161.00 & 670.00 & 3.00 & 8.00 & 374.00 & 114.00 & 30.00 \\
\hline 236708 & 11.00 & 111.00 & 71.00 & 156.00 & 675.00 & 3.00 & 7.00 & 373.90 & 127.00 & 42.60 \\
\hline 236701 & 10.00 & 115.00 & 65.00 & 151.00 & 385.00 & 3.00 & 9.00 & 302.60 & 132.90 & 45.10 \\
\hline 46003.00 & 9.00 & 101.00 & 49.00 & 142.00 & 335.00 & 3.00 & 8.00 & 147.00 & 76.00 & 57.00 \\
\hline
\end{tabular}

NPB, Number of primary branches/plant; PLH, plant height; DF, days-to-flowering; DM, days-tomaturity; NPP, number of pods/plant; SW, 100 seed weight; Bim, biomass; SYP, seed yield/plant; Hi, harvest index. 
Table 3. Mean squares for $\mathbf{9}$ quantitative morphological traits of $\mathbf{5 0}$ grass pea populations.

\begin{tabular}{llllll}
\hline Chracter code @ & Mean sq,for rep & Mean sq. for population & Mean sq. for error & CV & SE \\
\hline NPB & 2.434 & $2.064^{* *}$ & 0.974 & 10.58 & 0.14 \\
PLH & 128.488 & 238.661 & 171.224 & 11.82 & 1.85 \\
DF & 62.914 & $171.109^{* *}$ & 27.142 & 9.78 & 0.73 \\
DM & $335.605^{*}$ & $162.003^{* *}$ & 73.824 & 6.01 & 1.21 \\
NPP & 8331.588 & $30405.988^{* *}$ & 11309.8 & 27.41 & 15.03 \\
SW & 1.19 & $2.280^{* *}$ & 0.949 & 11.44 & 0.13 \\
Bim & 5557.791 & $9320.301^{* *}$ & 2976.59 & 29.25 & 7.71 \\
SYP & 746.793 & $1122.440^{*}$ & 744.363 & 31.66 & 3.85 \\
Hi & 41.771 & $183.348^{* *}$ & 55.527 & 15.81 & 1.05 \\
\hline
\end{tabular}

@ NPB, Number of primary branches/plant; PLH, plant height; DF, days-to-flowering; DM, daysto-maturity; NPP, number of pods/plant; SW, 100 seed weight; Bim, biomass; SYP, seed yield/plant; Hi, harvest index; * and ${ }^{* *}$ indicates significance at $5 \%$ and $1 \%$, respectively.

Variations in the various morphological characters were also observed by altitude groups (Table 5). The highest altitude group (group 4), which included populations collected from above $2550 \mathrm{~m}$ showed higher coefficient of variation for the morphological traits studied. Similarly the mean performance of the populations in this altitude group was much higher than others. As it can be expected days-to-flowering and days-to-maturity were minimum for populations in the low and mid altitude groups. The highest mean seed yield per plant was obtained from populations in the low altitude areas due to their short maturity period indicating the effectiveness of the crop to use efficiently the available short cycle moisture especially in the low moisture stress areas. In general, regions and altitude groups with high coefficient of variation were associated with high variability for the particular trait considered. The Gondar region has the highest CV for most traits studied indicating the presence of high genetic diversity of grass pea in the region.

\section{Cluster analysis}

Hierarchical clustering of the 50 grass pea landrace populations based on quantitative morphological characters was carried out (Fig. 1). The populations were grouped in two major clusters. Forty-eight populations were grouped in cluster I (CI) while only two populations, acc.no. 436705 and 236708, were grouped in cluster II (CII). These populations were collected from Gondar region at Woreta (1800 m.a.s.l.) and Dabat (2730 m.a.s.l.) districts. 


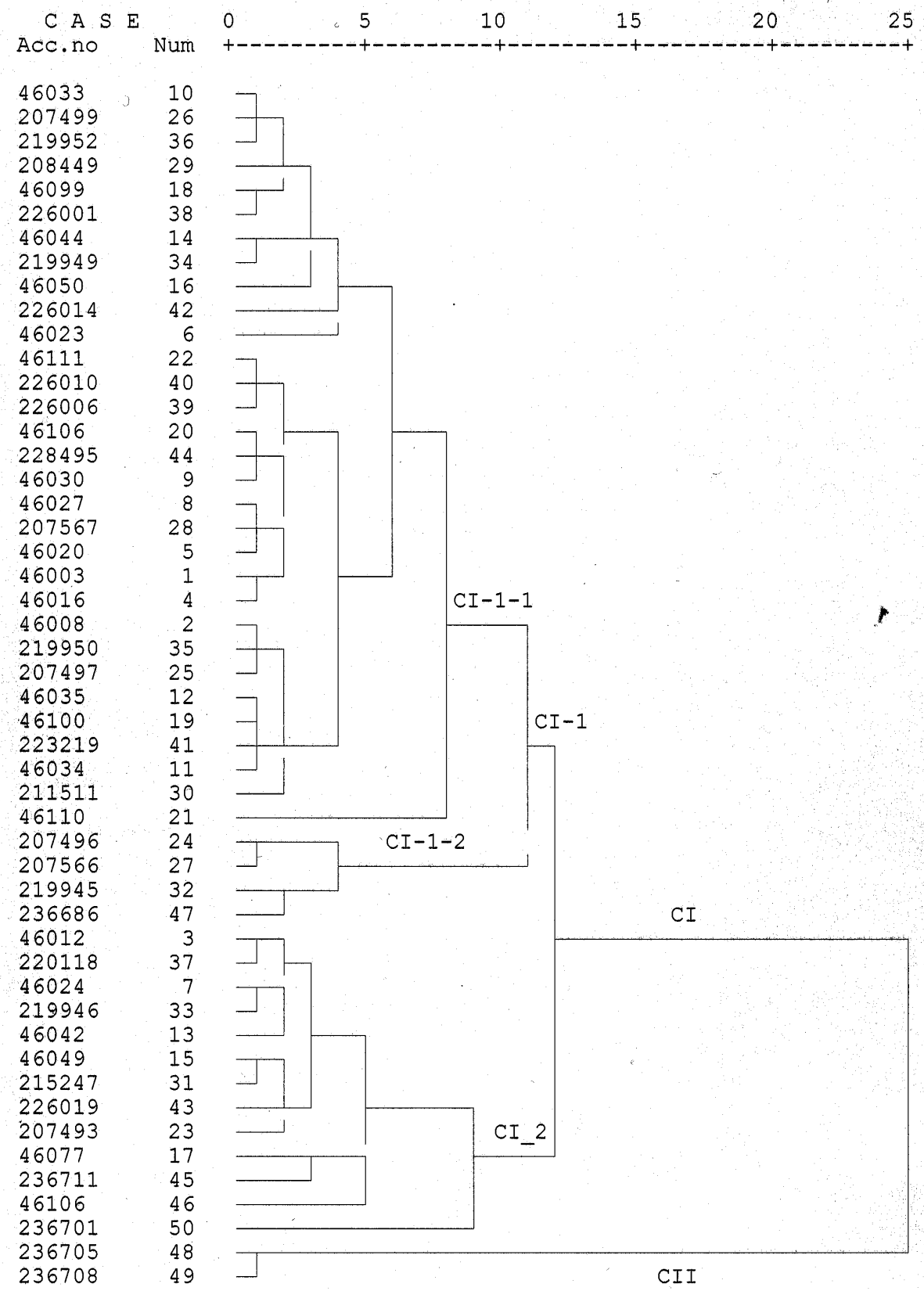

Fig. 1. Dendrogram for the 50 grass population based on morphological characters. 


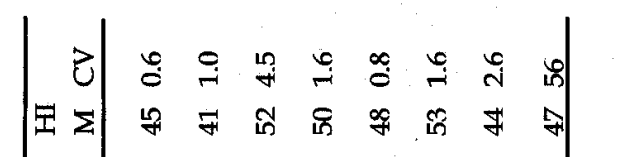

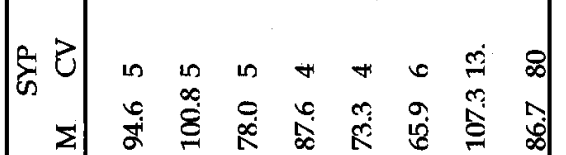

$$
\begin{aligned}
& \text { 苜己 } \\
& \text { इ }
\end{aligned}
$$

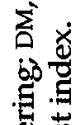

$$
\begin{aligned}
& \text { 苞苞 }
\end{aligned}
$$

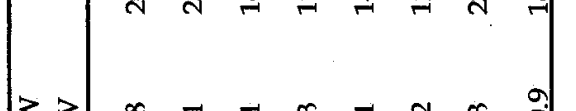

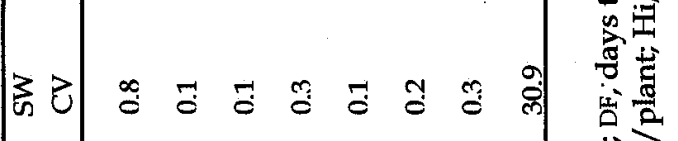

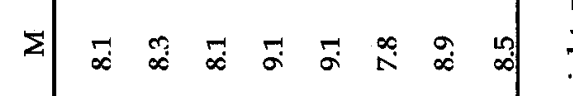

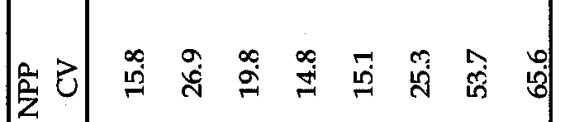

$$
\begin{aligned}
& \text { 焉 } \\
& \text { 它 }
\end{aligned}
$$

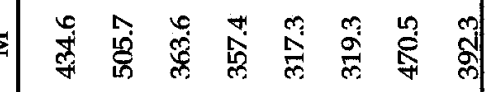

$$
\begin{aligned}
& \text { 武憵 }
\end{aligned}
$$




\section{Heritability, genetic advance and estimates for components of variance}

The phenotypic (PCV) and genetic (GCV) coefficient of variation, estimate of the component of variance, heritability (broad sense), and genetic advance (as percent of the mean) are given in Table 6. The phenotypic coefficient of variation (PCV) was slightly higher than genotypic coefficient of variation for all the characters studied signifying that genotypic factors had effect in estimating the variation. The wide difference between PCV $(22.4 \%)$ and GCV $(13.0 \%)$ for seed yield per plant indicates the complexity of this trait and the important role of other factors such as environment in influencing yield potential in addition to the genetic factors. A similar result was obtained by Getachew Belay (1997) in durum wheat.

Table 6. Summary statistics and estimates of phenotypic coefficient of variation (PCV) and genotypic coefficient of variation (GCV) broad sense heritability $\left(\mathrm{H}^{2}\right)$ and genetic advance (GS) in 50 grass pea populations for $\mathbf{9}$ quantitative traits.

\begin{tabular}{llllllllll}
\hline Characters & Mean & Range & Vp & Ve & Vg & $\begin{array}{l}\text { PCV } \\
(\%)\end{array}$ & $\begin{array}{l}\text { GCV } \\
(\%)\end{array}$ & $\mathrm{H}^{2}$ & $\begin{array}{c}\text { GS } \\
\text { (\% of mean) }\end{array}$ \\
\hline NPB & 9.02 & $8-12$ & 0.68 & 0.32 & 0.36 & 9.19 & 6.68 & 52.9 & 9.7 \\
PLH & 110.7 & $93-125$ & 79.5 & 57 & 22.4 & 8.05 & 4.28 & 28.2 & 4.6 \\
DF & 53.2 & $39-73$ & 57 & 9 & 47.9 & 14.22 & 13.02 & 84.14 & 24.5 \\
DM & 143 & $127-165$ & 54 & 25 & 29 & 5.13 & 3.79 & 54.4 & 5.7 \\
NPP & 387.9 & $199-675$ & 10135 & 3769.9 & 6365 & 25.9 & 20.5 & 62.8 & 33.5 \\
SW & 8.5 & $7-12$ & 0.76 & 0.31 & 0.45 & 10.2 & 7.8 & 59.2 & 12 \\
Bim & 186.5 & $86-374$ & 3106.8 & 992 & 2115 & 29.8 & 24.6 & 68 & 41.8 \\
SYP & 86.2 & $42-133$ & 374 & 248 & 126 & 22.4 & 13 & 33.6 & 15.2 \\
Hi & 47.1 & $30-85$ & 61 & 18.5 & 42.6 & 16.59 & 9.1 & 69.7 & 23.5 \\
\hline
\end{tabular}

${ }^{*} \mathrm{Vp}$, phenotypic variance; Ve, error variance; $\mathrm{Vg}$, genotypic variance.

The table shows that most of the characters had high heritability estimates indicating relatively less influence of the environment on them. Days-toflowering showed high heritability estimate $\left(h^{2}=84.14 \%\right)$. On the other hand, heritability estimate was low $\left(h^{2}=33.0 \%\right)$ for seed yield per plant and plant height $\left(h^{2}=28 \%\right)$, clearly indicating the major influence of the environment on these characters.

\section{Correlation analysis of quantitative characters}

Thorpe (1976) indicated that character associations are important to indicate common elements of epigenetic control and/or similar response of characters to selection pressure. In the present study, in all the regions (data not indicated here) and the entire data (Table 7), seed yield per plant was highly correlated with number of primary branches per plant, number of pods per plant and plant height. Similarly, we note a highly significant correlation 
between days-to-flowering and days-to-maturity. The presence of persistent correlation among most characters considered could be due to natural selection between individuals within a population which changes the genetic constitution of the population, but the mean fitness will not change if the population is already at the limit of the carrying capacity of its environment which of course is common in most cultivated plants (Endashaw Bekele, 1996). The highly significant correlations between the different characters also indicate the presence of some common elements of genetic control such as pleiotropy and high linkage between genes.

Table 7. Genotypic (G) and phenotypic (p) correlations in 9 quantitative morphological characters of 50 grass pea populations.

\begin{tabular}{|c|c|c|c|c|c|c|c|c|c|}
\hline Characters & NPB & PLH & $\mathrm{DF}$ & $\mathrm{DM}$ & NPP & SW & Bim & SYP & $\mathrm{Hi}$ \\
\hline NPB (G) & & .069 & $0.625^{\star *}$ & $0.707^{\text {** }}$ & $0.986^{* *}$ & -0.301 & $0.884^{\star *}$ & $0.905^{* *}$ & -0.28 \\
\hline$(\mathrm{P})$ & & 0.273 & 0.249 & 0.264 & $0.634^{* *}$ & -0.11 & $0.578^{* *}$ & $0.537^{* *}$ & $0.986^{* *}$ \\
\hline PLH (G) & & & $0.986^{* *}$ & $0.819^{* *}$ & $0.606^{* *}$ & $0.41^{* *}$ & $0.86^{* *}$ & $0.676^{* *}$ & $-0.677^{* *}$ \\
\hline$(\mathrm{P})$ & & & 0.261 & $0.547^{* *}$ & $0.606^{* *}$ & 0.11 & $0.605^{* *}$ & $0.629^{* *}$ & -0.105 \\
\hline DF (G) & & & & 1 & $0.891^{* *}$ & $-0.609 * *$ & $0.956^{* *}$ & 1 & -1.56 \\
\hline$(\mathrm{P})$ & & & & $0.578^{* *}$ & $0.407^{* *}$ & -0.314 & $0.426^{* *}$ & 0.205 & $-0.83^{* *}$ \\
\hline $\mathrm{DM}(\mathrm{G})$ & & & & & $0.813^{* *}$ & $-0.42^{* *}$ & 1 & $0.91^{* *}$ & $-0.69^{* *}$ \\
\hline$(\mathrm{P})$ & & & & & $0.535^{* *}$ & -0.16 & $0.55^{* *}$ & $0.43^{* *}$ & -0.23 \\
\hline $\operatorname{NPP}(\mathrm{G})$ & & & & & & $0.504^{* *}$ & $0.991^{* *}$ & $0.982^{* *}$ & $-0.50^{* *}$ \\
\hline$(\mathrm{P})$ & & & & & & 0.198 & $0.85^{* *}$ & $0.781^{* *}$ & -0.108 \\
\hline SW (G) & & & & & & & $-0.39^{*}$ & -0.134 & 0.184 \\
\hline$(\mathrm{P})$ & & & & & & & -0.103 & -0.02 & 0.232 \\
\hline $\operatorname{Bim}(G)$ & & & & & & & & $0.791^{* *}$ & $-0.619^{* *}$ \\
\hline$(\mathrm{P})$ & & & & & & & & 0.709 & -0.285 \\
\hline SYP (G) & & & & & & & & & $-0.606^{* *}$ \\
\hline$(\mathrm{P})$ & & & & & & & & & -0.006 \\
\hline $\mathrm{Hi}$ & & & & & & & & & \\
\hline
\end{tabular}

*, ** Indicates significance at $5 \%$ and $1 \%$, respectively.

The effect of environment on the genotypic performance of most traits was explained by many authors (Getachew Belay, 1997; Wuletaw Tadesse, 1998). Accordingly, splitting of genotypic and phenotypic correlations is important for clear understanding of character associations as indicated in Table 8. Genotypic and phenotypic correlations showed similar signs for most traits except for the association between number of primary branches per plant and harvest index for which the phenotypic correlation is strongly positive while the genetic coefficient is negative. In some cases the phenotypic and genotypic correlations were close in magnitude indicating that the impact of the environments over the traits mentioned is not significant. However, in other cases, the difference in the magnitude of the two coefficients is high indicating the effect of environmental variances and covariances as indicated in the case of the association between yield and harvest index where the genotypic 
correlation coefficient and the phenotypic correlation coefficients are -0.606 and -0.006 , respectively.

A strong positive genotypic correlation was observed between days-toflowering and seed yield per plant. A very strong genetic correlation was also noted between days-to-flowering and days-to-maturity. A similar result was reported by Getachew Belay (1997) in durum wheat. Plant height showed strong positive genetic correlation with most of the traits studied except with harvest index. The strong positive association of pods per plant, 100 seed weight and primary branches per plant with seed yield indicated the possibility of selecting lines for yield improvement based on these characters at the very early stage of the breeding program.

Table 8. Correlation among 10 different characters of 50 grass pea populations in Ethiopia.

\begin{tabular}{|c|c|c|c|c|c|c|c|c|c|c|}
\hline Character & Bim & DF & DM & $\mathrm{HI}$ & NPB & NPP & PLH & SPP & SW & SYP \\
\hline Bim & & $0.172^{* *}$ & $0.485^{* *}$ & -0.011 & $0.372^{* *}$ & $0.803^{* *}$ & $0.576^{* *}$ & $0.308^{* *}$ & 0.033 & $0.784^{* *}$ \\
\hline $\mathrm{DF}$ & & & $0.326^{* *}$ & -0.055 & $0.119^{* *}$ & $0.155^{* *}$ & 0.09 & $0.194^{* *}$ & -0.015 & 0.086 \\
\hline $\mathrm{DM}$ & & & & $0.136^{* *}$ & $0.194^{* *}$ & $0.518^{* *}$ & $0.604^{* *}$ & $0.465^{* *}$ & 0.044 & $0.455^{\text {** }}$ \\
\hline $\mathrm{HI}$ & & & & & 0.004 & $0.166^{* *}$ & $0.111^{* *}$ & $0.110^{* *}$ & -0.039 & $0.207^{* *}$ \\
\hline NPB & & & & & & $0.397^{* *}$ & $0.232^{* *}$ & $0.166^{* *}$ & 0.017 & $0.352^{* *}$ \\
\hline NPP & & & & & & & $0.589^{* *}$ & $0.379^{* *}$ & 0 & $0.787^{* *}$ \\
\hline PLH & & & & & & & & $0.379^{* *}$ & 0.005 & $0.557^{* *}$ \\
\hline SPP & & & & & & & & & -0.007 & $0.298^{* *}$ \\
\hline SW & & & & & & & & & & -0.003 \\
\hline SYP & & & & & & & & & & \\
\hline
\end{tabular}

NPB, Number of primary branches/plant; PLH, plant height; DF, days-to-flowering; DM, days-tomaturity; NPP, number of pods/plant; SW, 100 seed weight; Bim, biomass; SYP, seed yield/plant; Hi, harvest index.

\section{SUMMARY AND CONCLUSION}

Variation is the source of plant breeding without which crop improvement would be impeded. It is also important to improve germplasm collection and conservation. Mean, coefficient of variation (CV), heritability and correlation of characters are important tools to determine variation between populations in different regions and also in different altitude groups. The variability of 50 grass pea populations collected from different administrative regions and altitude groups in Ethiopia was investigated in this study. The results indicate the presence of high genetic diversity in Gondar region and the higher altitude class $(>2550 \mathrm{~m})$, which of course is important in setting priority during germplasm collection for ex situ conservation and selecting sites for in situ conservation in this region and altitude group. There was highly significant correlation between the different characters in all the entire data and the different regions indicating the presence of some common elements of genetic control such as pleiotropy and high linkage between genes. Strong positive genotypic and phenotypic correlations were observed between days-to- 
flowering and seed yield per plant. A very strong genetic correlation was also achieved between days-to-flowering and days-to-maturity. Plant height showed strong positive genetic correlation with most of the traits studied except with harvest index.

The strong positive association of pods per plant, 100 seed weight and primary branches per plant with seed yield indicated the possibility of selecting lines for yield improvement based on these characters at the very early stage of the grass pea breeding program. Furthermore, the variations in the morphological characters observed in the present study are important for future breeding program by analysing their ODAP variability.

\section{ACKNOWLEDGEMENTS}

This study was financially supported by the Institute of Biodiversity Conservation and Research, Ethiopia. The first author wishes to express his gratitude to the Amhara National Regional State for covering personal cost during the study.

\section{REFERENCES}

1. Abebe Demissie and Bjornstad, A. (1996). Phenotypic diversity of Ethiopian barleys in relation to geographical regions, altitudinal range, and agro-ecological zones: as an aid to germplasm collection and conservation strategy. Hereditas 124:17-29.

2. Asfaw Telaye, Geletu Bejiga and Alem Berhe (1994). Role of cool season food legumes in Ethiopia. In: Cool Season Food Legumes of Ethiopia. Proceedings of the First National Food legumes Conference, 16-20 December 1993, Addis Abeba, Ethiopia, pp. 3-18, (Asfaw Telaye, Saxena, M., Solh, M. and Geletu Bejiga, eds).

3. Bharati M.P. (1986). Status of Lathyrus sativus among grain legumes cultivated in Nepal. In: Lathyrus and lathyrism. Proceedings of the Colloquia Conference. Pawe, France, 1985, (Kaul, A.K. and Combes, D., eds). Third World Medical Research Foundation, New York.

4. Campbell, C.G. and Tiwari, K.R. (1997). Breeding grass pea for reduced seed levels of the neurotoxin (ODAP). In: Lathyrus and Lathyrism: A decade of Progress, pp. 85-86, (Redda Teklehaimanot and Lambein, F., eds). University of Ghent, Belgium.

5. CSA (1998). Agricultural sample survey, area and production of major crops. Statistical bulletin, 189 .

6. Dawit Tadesse (1994). Grass pea (Lathyrus sativus) Genetic resource conservation and utilization in Ethiopia. In: The Grass Pea and Lathyrism Conference in Ethiopia, pp. 61-66, (Berhanu Abegaz Molla, Redda Teklehaimanot, Palmer, V.S. and Spencer, P.S., eds). Third World Medical Research Foundation, New York.

7. Endashaw Bekele (1983). Some measure of gene diversity analysis on land race populations of Ethiopian barely. Hereditas 98:127-143. 
8. Endashaw Bekele (1996). Morphological analyses of Eragrostis teff: Detection for regional patterns of variation. SINET: Ethiop. J. Sci. 19(1):117-140.

9. Getachew Belay (1997). Genetic variation, breeding potential and cytogenetic profile of Ethiopian tetraploid wheat (Triticum turgidium L.) landraces. Doctoral thesis, Swedish University of Agricultural Sciences, Uppsala, Sweden.

10. Goyder, D.J. (1986). The Genus Lathyrus. In: Lathyrus and lathyrism. Proceedings of the Colloquia Conference. Pawe, France, 1985, pp. 3-7, (Kaul, A.K. and Combes, D., eds). Third World Medical Research Foundation, New York.

11. Jaradat, A. (1991). Phenotypic divergence for morphological and yield related traits among landrace genotypes of durum wheat from Jordan. Euphytica 52:155-164.

12. Johanson, H.W.; Robinson, H.F. and Comstock, R.E. (1955). Estimates of genetic and environmental variability in soyabeans. Agronomy journal 47:314-320.

13. Kaul, A.K.; Islam M.Q. and Humid, A. (1986). Screening of Lathyrus germplasms of Bangladesh for BOAA content and some agronomic characters. In: Lathyrus and lathyrism. Proceedings of the Colloquia Conference. Pawe, France, 1985, pp. 130-141, (Kaul, A.K. and Combes, D., eds) Third World Medical Research Foundation, New York.

14. Lal, M.S., Agrawal, I. and Chitale, M.W. (1986). Genetic improvement of chickling vetch in Madhaya Pradesh, India. In: Lathyrus and lathyrism. Proceedings of the Colloquia Conference. Pawe, France, 1985, pp. 146-160, (Kaul, A.K. and Combes, D., eds). Third World Medical Research Foundation, New York.

15. Melaku Werede (1988). Diversity and the genetic resource base. Ethiopian J. Agric. Sci. 10 (1-2):39-52.

16. Purseglove, S.W. (1968). Tropical crops: Dycotyledons. Printhouse, Singapore.

17. Sharma, S.; Chahota, K. and Lal, C. (1995). Genetic diversity and agronomic evaluation of microsperma and macrosperma lentils. Genetic Resource and Crop Evolution 42:217-222.

18. Thorpe, R.S. (1976). Biochemical analysis of geographical variation and racial affinities. Biol. Rev. 52:407-452.

19. Thulin, M. (1983). Leguminosae of Ethiopia. Opera Bot. 68:1-23.

20. Vavilov, N.I. (1951). The origin, variation, immunity and breeding of cultivated plants. Chron. Botan. 13:1-36.

21. Wuletaw Tadesse (1999). Morphological and biochemical diversity of grass pea (Lathyrus satious L.) in Ethiopia. MSc Thesis in Biology (Applied genetics), Addis Ababa University, Ethiopia.

22. Wuletaw Tadesse (1998). Effect of genotype $x$ environment interaction on Neourotoxin content and grain yield of grasspea. In: Crop Management Options to Sustain Food Security: Proceedings of the third conference of Agronomy and crop physiology society of Ethiopia (ACPSE), 29-30 May 1997, Addis Ababa, (Kidane Georgis and Yohannes Degago, eds). ACPSE, Addis Ababa, Ethiopia.

23. Wuletaw Tadesse, Yohannes Degago and Asfaw Telaye (1997). Grass pea (Lathyrus sativus): Production and breeding in Ethiopia. In: Lathyrus and Lathyrism: A decade of Progres, pp. 87-90, (Redda Teklehaimanot and Lambein, F., eds). University of Ghent, Belgium. 